\title{
Modelling the Implications of Quality Management Elements on Strategic Flexibility
}

\section{Ana Belén Escrig-Tena, Juan Carlos Bou-Llusar, Inmaculada Beltrán-Martín, and Vicente Roca-Puig}

Departamento de Administración de Empresas y Marketing, Universitat Jaume I, Campus del Riu Sec, 12071 Castellón, Spain

Correspondence should be addressed to Ana Belén Escrig-Tena, escrigt@emp.uji.es

Received 10 August 2011; Accepted 12 December 2011

Academic Editor: David Bulger

Copyright (C 2011 Ana Belén Escrig-Tena et al. This is an open access article distributed under the Creative Commons Attribution License, which permits unrestricted use, distribution, and reproduction in any medium, provided the original work is properly cited.

This paper presents a theoretical and empirical analysis of the implications of a quality management (QM) initiative on strategic flexibility. Our study defines flexibility from a strategic approach and examines the extent to which, why, and how the triggering factors of strategic flexibility are related to QM elements. The hypotheses put forward are tested in an empirical study carried out on a sample of Spanish firms, using structural equation models. The results demonstrate the positive effect of adopting an integral QM initiative on enhancing strategic flexibility. QM enhances strategic flexibility more effectively when it is introduced comprehensively rather than in a piecemeal fashion. A series of practices linked to the application of a QM initiative are outlined, which managers can use to improve strategic flexibility. The approach used in the study can be applied to analyse other antecedents of flexibility and to propose possible studies that consider QM as an antecedent of other organisational variables.

\section{Introduction}

Over the last few decades, quality management (QM) models have been adopted to improve performance and achieve sustainable excellence. Although QM is a recognised means of pursuing higher performance and facilitating the realisation of excellent results, the literature has discussed whether QM fosters change and flexibility or whether, on the contrary, it hinders the firm's interest in new developments since it aspires to stability and reliability [1-3]. Consequently, after a long period in which QM has evolved considerably, it is now necessary to determine whether the practices and actions imposed by these initiatives provide effective means to respond with the flexibility necessary in the new competitive conditions.

Strategic flexibility is particularly important in the new competitive environment [410] since it involves the firm's abilities to respond to problems speedily, rethink its activities 
and strategies, and better meet environmental demands. As Hitt et al. [6, page 22] state, "success in the 21st century organisation will depend first on building strategic flexibility."

Some papers in the literature suggest that QM and flexibility go together $[4,11]$. Empirical studies such as those by González and Dale [12] and Merino [13] show how the most advanced organisations in QM are achieving better operational performance in terms of flexibility. For their part, Gómez and Verdú [14] conclude that companies with QM programs, compared to those without QM, are associated with greater levels of flexibility and a better fit with the requirements of the environment. Gutiérrez and Pérez [15] go a step further to conclude that there are similarities between the structural elements of quality models and the elements required to achieve flexibility. In spite of the interesting implications of these papers, these authors do not fully analyse how and why QM elements work to enhance strategic flexibility.

Our study attempts to extend understanding of the relationship between QM and flexibility by undertaking an in-depth analysis of the extent to which QM elements might be considered antecedents of strategic flexibility. We attempt to provide evidence of QM elements that induce flexibility, that is, practices associated with QM that are able to explain how firms develop strategic flexibility. We complement previous studies in several ways. First, we adopt a strategic approach to flexibility that defines flexibility as the firm's abilities to better adjust to environmental demands and rethink its activities and strategies, rather than considering it as an operational result. Second, we develop an overall quality model that embraces a broad range of QM elements and investigate both the contribution that specific elements may make and the impact QM may have as a whole. Our findings will contribute to the literature by furthering understanding of strategic flexibility enablers and by thoroughly exploring the extent to which QM elements are linked to stability or change.

To meet this aim, we used a cross-sectional survey methodology. The hypotheses put forward are tested in an empirical study carried out on a sample of Spanish service and industrial firms using structural equations modelling. The rest of the study is structured as follows. Firstly, the delimitation of strategic flexibility is analysed and the enablers of strategic flexibility are discussed. We then analyse the extent to which QM elements can be considered as precursors of flexibility and present the models for the relationships between QM and strategic flexibility. Finally, we report the results of the empirical study and draw conclusions.

\section{Theory Development}

\subsection{Strategic Flexibility and Its Enablers}

There is no unification of terminology nor single definition of the term flexibility; it is a complex concept that has been defined in numerous ways since the 1950s [4, 5, 16-22]. Our paper centres the concept of flexibility on the strategic approach pointed by De Toni and Tonchia [22]. Taking into account this approach, Table 1 synthesises some definitions of strategic flexibility in the extant literature.

Following Slack [23] and as can be seen in Table 1, numerous authors conclude that strategic flexibility is manifested in the organisation through the adoption of diverse and rapid responses to cope with environmental contingencies. Accordingly, our research understands strategic flexibility as the firm's capability to respond quickly and in a varied way to the changes coming from the environment and thereby develop and/or maintain competitive advantage. It represents the potential a firm has to transform itself. As Evans [24, page 77] 
Table 1: Definitions of strategic flexibility.

\begin{tabular}{|c|c|c|}
\hline Authors & Definition & $\begin{array}{l}\text { Main feature of the } \\
\text { definition }\end{array}$ \\
\hline Lau [115] & $\begin{array}{l}\text { Firm's ability to respond to uncertainties by } \\
\text { adjusting its objectives with the support of its } \\
\text { superior knowledge and capabilities }\end{array}$ & $\begin{array}{l}\text { Respond by adjusting } \\
\text { objectives }\end{array}$ \\
\hline $\begin{array}{l}\text { Das and Elango } \\
{[28]}\end{array}$ & $\begin{array}{l}\text { The ability of an organisation to respond to } \\
\text { changes in the environment in a timely and } \\
\text { appropriate manner with due regard to the } \\
\text { competitive forces in the environment }\end{array}$ & $\begin{array}{l}\text { Respond in a timely } \\
\text { and appropriate } \\
\text { manner }\end{array}$ \\
\hline Sanchez [116] & $\begin{array}{l}\text { Firms' abilities to respond to various demands } \\
\text { from dynamic competitive environments }\end{array}$ & Abilities to respond \\
\hline $\begin{array}{l}\text { De Toni and } \\
\text { Tonchia [22] }\end{array}$ & $\begin{array}{l}\text { The speed at which competitive priorities can } \\
\text { be varied and the speed of shifting from one } \\
\text { business to another }\end{array}$ & $\begin{array}{l}\text { Variety } \\
\text { Speed }\end{array}$ \\
\hline Hitt et al. [6] & $\begin{array}{l}\text { Capability of the firm to proact or respond } \\
\text { quickly to changing competitive conditions } \\
\text { and thereby develop and/or maintain } \\
\text { competitive advantage }\end{array}$ & $\begin{array}{l}\text { Respond quickly to } \\
\text { gain competitive } \\
\text { advantage }\end{array}$ \\
\hline Evans [24] & $\begin{array}{l}\text { Capability which enables organisations to } \\
\text { mutate }\end{array}$ & Modification \\
\hline $\begin{array}{l}\text { Volberda }[17,18] \\
\text { Prastacos et al. } \\
{[29]}\end{array}$ & $\begin{array}{l}\text { A type of flexibility that comprises the } \\
\text { "flexibility mix" together with operational and } \\
\text { structural flexibility, is the most radical type; it } \\
\text { is much more qualitative and involves } \\
\text { changes in the nature of organisational } \\
\text { activities, as opposed to the volume or the } \\
\text { structural organisation of activities }\end{array}$ & $\begin{array}{l}\text { Changes in the nature } \\
\text { of organisational } \\
\text { activities }\end{array}$ \\
\hline $\begin{array}{l}\text { Shimizu and Hitt } \\
\text { [8] }\end{array}$ & $\begin{array}{l}\text { Capability to identify major changes in the } \\
\text { external environment, to quickly commit } \\
\text { resources to new courses of action in response } \\
\text { to change, and to recognise and act promptly } \\
\text { when it is time to reverse such resource } \\
\text { commitments }\end{array}$ & $\begin{array}{l}\text { Ability to commit and } \\
\text { reverse resources to } \\
\text { new actions quickly }\end{array}$ \\
\hline $\begin{array}{l}\text { Price et al. [117] } \\
\text { Beach et al. [118] }\end{array}$ & $\begin{array}{l}\text { The number of different strategies which the } \\
\text { firm could readily follow if it decided to move } \\
\text { from its current position }\end{array}$ & $\begin{array}{l}\text { Scope of variation } \\
\text { Speed of variation }\end{array}$ \\
\hline
\end{tabular}

Source: the authors.

states, "organisations seek strategic flexibility in order to increase the speed and extend their scope of manoeuvre." Speed refers to how quickly an organisation acts in the face of environmental and competitive pressures $[16,17]$. Central to the notion of strategic flexibility is the capability to generate variety so that options are available to do things differently or do something else if the need arises [24].

According to Koste and Malhotra [20], our concept of strategic flexibility falls within the upper tier of a hierarchy of flexibility types, where the lower tiers contain more tactical types of flexibility that serve as building blocks for those in the upper tiers $[5,25]$. It fits the concept of agility as understood by Baker [26]. According to this author, whilst agility places greater focus on the strategic levels, the term flexibility is usually associated with the operational level. Flexible operations are needed in order to provide agility at the organisational and business network levels $[10,26,27]$. 
Few studies in the literature directly analyse the antecedents or building blocks of strategic flexibility. Das and Elango [28] explore this matter, explaining that it can be achieved in the organisation in several ways, both internal (manufacturing flexibility, modular product design, employee flexibility, and organisational structure) and external (suppliers, alliances, multinational operations). Hitt et al. [6] consider that the new competitive landscape will require new types of organisations and leaders and provide some steps for managers to follow in building strategic flexibility, including exercising strategic leadership or developing human capital. For their part, Prastacos et al. [29] state that flexibility is one of the imperatives that organisations should take into account in the new competitive landscape and develop a model of organisational change that seeks to offer managers guidance on the fundamental ways of developing strategic flexibility in an organisation. Their proposal entails applying the appropriate levers of change in strategy, structure, processes, and human capital management practices. Shimizu and Hitt [8] state that strategic flexibility requires use of three capabilities: maintaining attention, completing an assessment, and taking action. They identify several barriers that block the development of these capabilities and recommend six practical steps to avoid them. The authors describe the purpose of these steps as follows: "six principles to build organisational preparedness that allow managers and organisations to effectively maintain attention to negative signs, evaluate and analyse outcomes objectively, and initiate actions that reverse, when necessary, previous strategic decisions" [8, page 51]. Other authors focus on specific factors that foster flexibility. Some of the most relevant include Worren et al. [7], who emphasise the importance of modular product design, Liebeskind et al. [30] and Gutiérrez and Pérez [15] who examine social networks as enablers of flexibility, or Zhang [31] and Celuch et al. [32] who investigate the impact of information systems on strategic flexibility.

The right-hand column of Table 2 summarises the literature that provides suggestions on how to enhance strategic flexibility, grouped according to the similarities between the enabling factors recommended.

Table 2 summarises some of the enabling factors suggested to achieve strategic flexibility. Among them is exercising strategic leadership $[4,6]$. These authors state that managers must be a catalyst for change, which can be achieved by providing strategic leadership: developing and communicating a long-term vision, encouraging and gaining employee commitment to continuous change, and building nonlinear thinking among management teams and all employees. In this way managers are able to create a mindset that emphasises change and flexibility.

In order to be flexible, organisations need to use strategy as an incubator for change [29, page 61], in other words, as a means to absorb, reformulate, and disseminate throughout the organisation a series of frameworks that help employees at all levels to constantly reexamine what the firm is doing. In this sense, strategy formulation is a continuous process, where business plans are revised at appropriate and flexible intervals [29, page 61].

In the same line, organisations can gain flexibility by optimal use of manufacturing and information technology. Manufacturing technology allows firms to change various aspects of production and product design in line with market needs [28]. Information technology supports the rapid collection and dissemination of information about markets or internal information about the development of processes that can aid firms in making faster and higher-quality strategic decisions and in developing and moving new products to the market more quickly [6, page 32] and [31,32]. These information technologies enable managers to measure and monitor decisions, to be aware of the outcomes of decisions, and to change them if necessary. 
Table 2: Enabling factors of strategic flexibility.

\begin{tabular}{|c|c|c|}
\hline QM elements & Enabling factors of strategic flexibility & Authors \\
\hline Leadership & Leadership & Upton [4], Hitt et al. [6] \\
\hline $\begin{array}{l}\text { Strategic } \\
\text { planning }\end{array}$ & Strategy as an incubator for change & $\begin{array}{l}\text { Prastacos et al. [29], Shimizu and Hitt } \\
\text { [8] }\end{array}$ \\
\hline $\begin{array}{l}\text { Information } \\
\text { and analysis }\end{array}$ & $\begin{array}{l}\text { Measure and monitor decision outcomes } \\
\text { Use of new manufacturing and information } \\
\text { technologies }\end{array}$ & $\begin{array}{l}\text { Shimizu and Hitt [8], Volberda [18], } \\
\text { Das and Elango [28], Hitt et al. [6], } \\
\text { Prastacos et al. [29], Zhang [31], } \\
\text { Palanisamy [119], Celuch et al. [32] }\end{array}$ \\
\hline $\begin{array}{l}\text { Human } \\
\text { resource } \\
\text { management }\end{array}$ & $\begin{array}{l}\text { Develop human capital } \\
\text { Comprehensive training } \\
\text { Teamwork }\end{array}$ & $\begin{array}{l}\text { Youndt et al. [61], Das and Elango } \\
\text { [28], Manz and Stewart [101], } \\
\text { Volberda [18], Hitt et al. [6], Kara et al. } \\
\text { [33], Prastacos et al. [29], Shimizu and } \\
\text { Hitt [8], Gilson et al. [65] }\end{array}$ \\
\hline $\begin{array}{l}\text { Supplier } \\
\text { management }\end{array}$ & $\begin{array}{l}\text { Use of cooperative strategies or belonging } \\
\text { to a network } \\
\text { Create dynamic mechanism to gain new } \\
\text { ideas from outside the firm }\end{array}$ & $\begin{array}{l}\text { Liebeskind et al. [30], Das and Elango } \\
\text { [28], Hitt et al. [6], Bahrami [69], } \\
\text { Prastacos et al. [29], Shimizu and Hitt } \\
{[8]}\end{array}$ \\
\hline $\begin{array}{l}\text { Processes } \\
\text { management }\end{array}$ & Processes management & $\begin{array}{l}\text { Prastacos et al. [29], Worren et al. [7], } \\
\text { Shimizu and Hitt [8] }\end{array}$ \\
\hline \multirow[t]{7}{*}{$\begin{array}{l}\text { Customer } \\
\text { focus }\end{array}$} & $\begin{array}{l}\text { Customer orientation in product and } \\
\text { service development }\end{array}$ & $\begin{array}{l}\text { Prastacos et al. [29], Johnson et al. } \\
\text { [21], Javalgi et al. [120] }\end{array}$ \\
\hline & Exploit global markets & Hitt et al. [6], Das and Elango [28] \\
\hline & $\begin{array}{l}\text { Develop new organisational structures and } \\
\text { culture }\end{array}$ & Hitt et al. [6], Shimizu and Hitt [8] \\
\hline & $\begin{array}{l}\text { Stimulate decision-making processes by } \\
\text { incorporating a devil's advocate approach }\end{array}$ & Shimizu and Hitt [8] \\
\hline & Consider decisions portfolios & Shimizu and Hitt [8] \\
\hline & $\begin{array}{l}\text { Recognise the limitations of static } \\
\text { governance systems }\end{array}$ & Shimizu and Hitt [8] \\
\hline & Build dynamic core competences & Hitt et al. [6] \\
\hline
\end{tabular}

Source: the authors.

Hitt et al. [6], Prastacos et al. [29], and Kara et al. [33] note the conditions in which human resource management can promote flexibility. Firms need to invest in the development of human capital, promote team-based decision making, and consider employees as experts in their jobs. Consciousness of employees' behaviours and needs and empowerment become necessary in order to extract the best from human capital [29, page 67]. In doing so, firms will have the knowledge and skills to make the changes needed in the new competitive landscape.

Another way for an organisation to gain strategic flexibility is to establish a network with other firms, such as suppliers [28]. Setting up vigorous supplier selection procedures based on quality and technology and establishing strong collaborative ties with selected suppliers is one way to achieve the imperative of flexibility [29]. As these authors state, this allows buyers and suppliers to learn together about new product development and to incorporate new ideas as part of their relationship. Other forms of cooperative strategies such as strategic alliances and networks may also be used to develop complementary competences in order to adapt to market changes and requirements.

Processes are also a major key to flexibility. The process notion embraces all valuecreating flows of tangibles and intangibles. In this sense, Prastacos et al. [29] stress the role of 
processes as the main contributors to value creation and as vehicles for realising the unique capabilities needed to change.

Following Prastacos et al. [29], the customer is becoming the "king" of the competitive game. Managers need to identify and implement new ways of delivering customer value, since this is the fundamental prerequisite for success. Employees must be close to customers and bring the customer into the organisation, by fostering trust and openness with customers. This provides the opportunity for firms to understand their customers and develop their business relationship with them [29, page 62].

Some authors point to the need to exploit global markets $[6,28]$ as a way of achieving flexibility. The flexibility of this approach is advantageous to the firm because it allows the production of value-added activities to be shifted from one country to another.

Structure needs to become a flexible skeleton, where traditional hierarchies are transformed into decentralised power structures, horizontal structures enabling people to access information and collaboration in teams in order to take rapid action and guarantee the required response to the market $[6,29]$. Furthermore, flexibility can also be facilitated by a learning and innovative culture where employees feel free to act and where there is room for testing and experimenting with new ideas [29].

In addition to the enablers discussed above, Shimizu and Hitt [8] mention some other issues related to the decision-making process that can build organisational preparedness. They propose analysing appropriate alternatives and opportunities more thoroughly and from many different vantage points, by having a member of the top management team adopt the role of devil's advocate, by maintaining a portfolio of multiple decisions or by incorporating a more dynamic view of board membership that improves governance effectiveness.

Finally, organisational core competences represent the firm's capacity to implement and sustain the changes required to be flexible and innovative [29, page 57]; these cannot remain static but must be exploited and leveraged to develop new products and new markets [6].

By affecting these enablers, it would be possible to improve the company's capability in terms of strategic flexibility. Some of the factors identified by these authors seem to be closely associated with quality management (QM) elements. Table 2 reflects this association and suggests the correspondence between each QM element and the enabling factors of flexibility. This issue is more extensively addressed in the next section.

\subsection{Quality Management as Driver of Strategic Flexibility}

From a review of previous contributions [1,34-38], a dominant insight among experts seems to define QM as an approach to management characterised by some guiding core elements that embody the way the organisation is expected to operate, which, when effectively linked together, will lead to high performance.

We agree with Tarí et al. [38] or Sila [39] when they show that there is no unanimous view of the elements that form the QM concept. Nevertheless, a comparison of QM practices across different studies (see Table 3) allows us to identify some elements that include the practices making it possible to introduce QM into an organisation: leadership, strategic planning, information and analysis, human resource management (HRM), supplier management, process management, and customer focus.

Table 3 shows that QM elements included in our research are consistent with those used by pioneer studies in QM practices and coincide with the QM practices considered by Sila and Ebrahimpour [40] and Sila [39]. These elements are also consistent with the enablers 
Advances in Decision Sciences

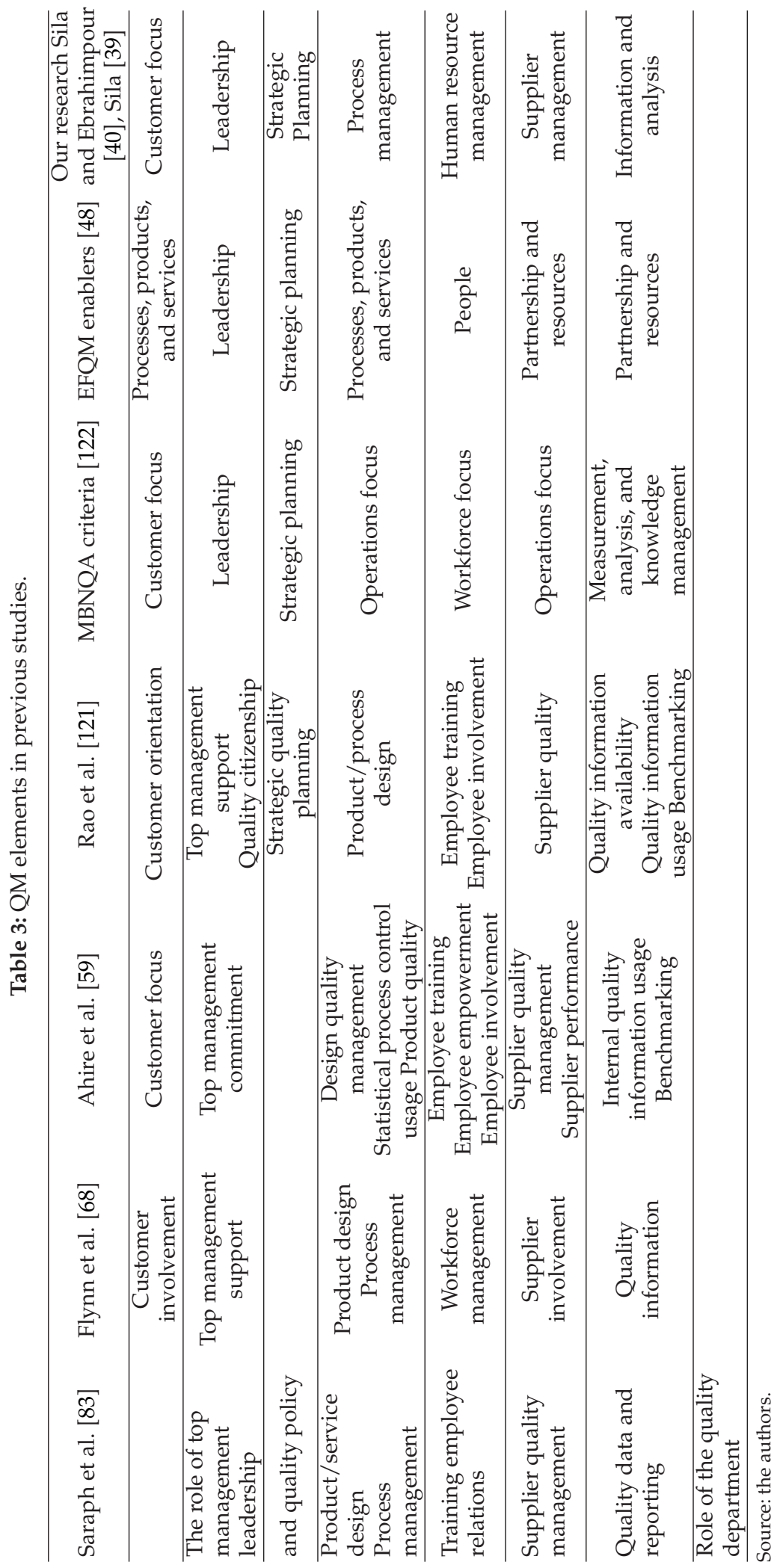


of the EFQM Excellence Model and the Malcolm Baldrige National Quality Award (MBNQA) criteria, considered to constitute a valid representation of QM [41, 42].

The influence of QM on flexibility is noted in several studies. In this sense, Hill's study [43] argues that QM can increase flexibility through the interfunctional coordination techniques it provides, the increase in the organisation's awareness of customer requirements, and the practices it makes use of in the area of human resources. Empirical studies like González and Dale [12], Merino [13], or Gómez and Verdú [14] show how the organisations that are most advanced in QM achieve better results in terms of flexibility.

There are some papers that, although they do not talk about strategic flexibility, address the influence of QM on the capability to change and on firm responsiveness. In this sense, Hackman and Wageman [35] state that QM organisations whose core values are orientation to learning, commitment to management by fact, and close links with customers, among others, are specifically tailored to foster responsiveness to environmental changes. Youssef et al. [44] argue that responsiveness and QM cannot be divorced since QM affects not only the quality but also the ability of the firm to respond to customer needs in an agile and quick manner. Feldman and Pentland [45] consider QM as an important megaroutine for fostering change. Along similar lines, Prajogo and Sohal [46] and Hoang et al. [47] suggest that the multidimensional nature of QM makes it possible to improve innovation and change and can promote the existence of an ambidextrous organisation that combines mechanical aspects with more organic elements based on learning.

Additionally, the EFQM Excellence Model is based on eight fundamental concepts, a set of beliefs about what it means to be an excellent organisation [48]. Some of these fundamental concepts-achieving balanced results, leading with vision, inspiration, and integrity, succeeding through people, and nurturing creativity and innovation-explicitly recognise that excellence entails the capability to realign the direction of the organisation, the responsiveness to changing stakeholders' needs, individuals' capability to adapt to changes, and organisational agility. These references to flexibility in the EFQM Excellence Model point to a potential relationship between QM elements and flexibility that demands further exploration.

Therefore, since QM elements involve adopting some specific organisational behaviours, a certain approach to structuring the organisation, and relating to competitors, suppliers, and customers in a particular way, they may be considered as an attempt to generate effective responses to the increasingly complex and dynamic environment. Below, we analyse how each QM element can influence strategic flexibility (see Figure 1(a)).

\subsubsection{Leadership}

Hitt et al. [6] establish that in order to help improve strategic flexibility, managers must be a catalyst for change. Precisely, this management role is recognised in the leadership element of QM. This element implies the capacity of managers to change and to adapt to changing conditions [48-51]. More specifically, following these authors, leadership in QM means that managers should develop values and systems that highlight the importance of the customer, teamwork, training, communication, and cooperation aimed at involving people in improvement activities. The introduction of a QM initiative, therefore, requires managers to play new roles, stimulating their role as coaches, in order to generate the trust necessary to encourage members of the company to follow their leader. This role enables managers to have a strong network of relationships that provides them with an extensive flow of information and knowledge. Following Hitt et al. [6], leaders with a wider range of expertise and knowledge are more likely to identify environmental changes quickly and to put into 


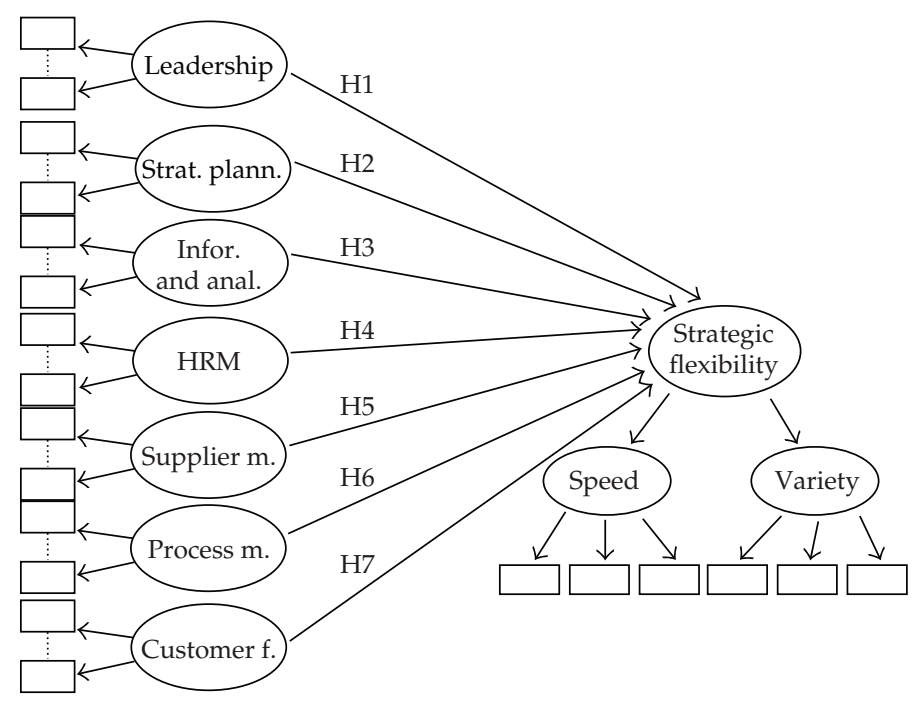

(a) Multivariate model for QM elements

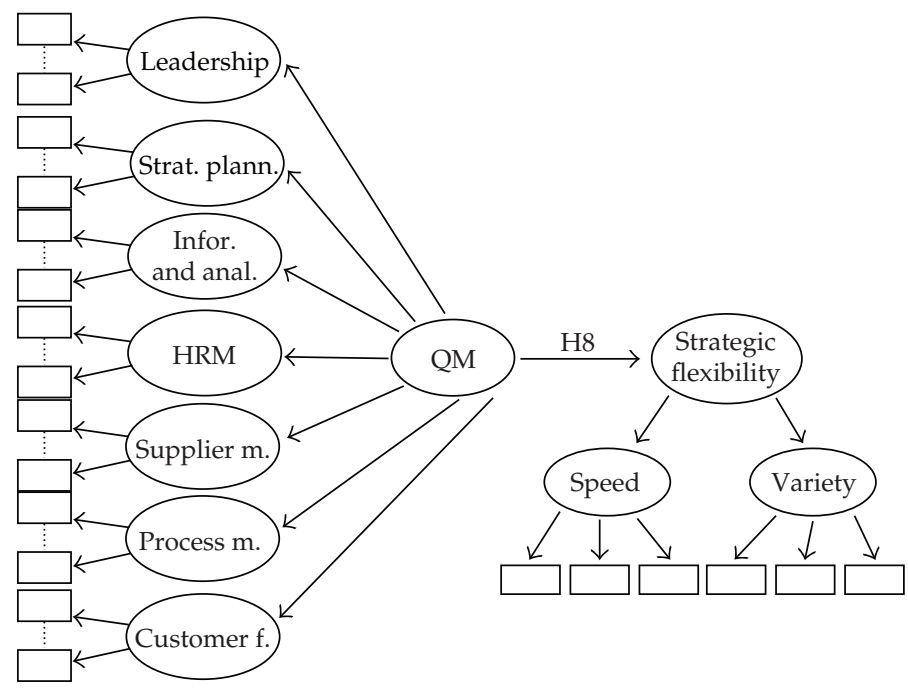

(b) Multidimensional model for QM

Figure 1: Proposed models.

practice a variety of changes within the firm. Moreover, they are able to react quickly due to the ability to manage, coordinate, and communicate the phenomena that promote changes. In this way, the introduction of a QM initiative lays the foundations for effective leadership by contributing to improving flexibility. We, therefore, posit the following hypothesis.

Hypothesis 1. Leadership is positively related to strategic flexibility.

\subsubsection{Strategic Planning}

Following Dean and Bowen [34], Tummala and Tang [52], Staggs [53], Samson and Terziovski [54], Sila and Ebrahimpour [40], and EFQM [48], the strategic planning element 
underlines a systematic approach that may help firms to clarify their central purpose and organisational goals and deploy objectives for achieving these goals.

QM proponents consider that, as with any other business process, the process of strategy formulation and implementation should be continuously subjected to analysis and improvement [34, page 405]. In our view, this conception of the strategy process overlaps with the idea of strategy as an incubator for change, as it understands strategy formulation as a continuous process, where business plans are revised at appropriate and flexible intervals. Accordingly, it enables the firm's position to change quickly when the need arises because of this regular revision of strategy. In addition, as Castresana and Fernández [51] note, business strategy offers a way of meeting the present and future needs and expectations of the main stakeholders, enabling the firm to have a varied range of strategies that combine all stakeholder perspectives. Based on these arguments, we suggest the following.

Hypothesis 2. Strategic planning is positively related to strategic flexibility.

\subsubsection{Information and Analysis}

QM emphasises fact-based decision making, involving analysis of information about customers and internal and external measures of organisational results [48, 50,54]. As Dean and Bowen [34] state, the QM literature "suggests that organizations that consistently analyze information will be more successful than those that do not." In our view, self-assessment activities, benchmarking, internal and external measures of organisational results, and the use of environmental information ensure the organisation has a large amount of information necessary to detect changing customer needs, new markets, and new types of activities that demand a new organisational response and new productive combinations, thus improving strategic flexibility. For example, by timely collection and dissemination of important quality data and information throughout the organisation, managers and employees can quickly detect quality problems and take actions [55-57], thus improving firm responsiveness. In addition, Hatum and Pettigrew [58] argue that mechanisms to scan the environment increase information use and the likelihood of interpreting issues quickly and help organisations be more proactive and complete successful changes. This leads us to posit the following.

Hypothesis 3. Information and analysis are positively related to strategic flexibility.

\subsubsection{Human Resource Management}

The literature has recognised the relevance of human resource management (HRM) to the implementation of QM [34, 38, 40, 49, 50]. For this purpose, the components most frequently referred to are training, employee involvement through teamwork, and empowerment [59]. These HRM components create a suitable environment for employee motivation and enable employees to improve the way work is done. In fact, Bayo and Merino [60] found that QM is being adopted alongside high-performance work practices.

Training in QM initiatives fosters problem solving and interpersonal skills, which are of great value in pursuing strategic flexibility since they facilitate adaptability and responsiveness [61]. As Chadwick and Cappelli [62] point out, training furthers flexibility because workers who have received multidisciplinary training can be reassigned in line with the changing demands facing the organisation. 
As Judi et al. [63] suggest, empowerment allows knowledge to be used more quickly and effectively, in order to respond to change in a dynamic environment, and enables problems to be solved as soon as they are detected, without the need to report to higher levels or other departments, so response time and flexibility are improved. By way of example, the results of the study by Sim and Curatola [64], based on research carried out at 83 electronics plants, conclude that companies that have delegated decision-making authority in the workplace show a proportionally greater reduction in product development time than those that have not implemented this practice.

Moreover, Kara et al. [33] and Gilson et al. [65] find that team creativity enables organisations to stay flexible. Accordingly, creating groups made up of people with different perspectives can enhance creativity and help develop new products more quickly than the traditional sequential processes followed by hierarchical organisations.

In addition, Grant et al. [66] argue that, when a QM initiative is applied, information flows become more horizontal rather than vertical, organisations tend to design more flexible structures, and the scope of control is expanded, making the organisation's power structure flatter. Flatter and more horizontal structures enhance innovation and speed in strategic actions [6, pages 35,36$]$.

All these HR components promote a diversity of opinions and perspectives and encourage employees to feel free to act, which in turn generates new ideas and creativity, as Prastacos et al. [29] point out. Through its influence on the organisational support that employees perceive, these kinds of HRM practices favour the adoption of discretionary efforts by employees and complement strategic flexibility [6,67]. The above arguments lead us to put forward the following hypothesis.

Hypothesis 4. Human resource management is positively related to strategic flexibility.

\subsubsection{Supplier Management}

This QM element advocates the generation of cooperative alliances with suppliers based on long-term common interests $[40,50,59,68]$. As Ahire et al. [59, page 28] highlight, "supplier's capability to react to a buyer firm's needs, in turn, can determine the buyer's flexibility in responding to the customer's needs." Following Bahrami [69], cooperative relationships are an excellent mechanism for providing the organisation with additional capabilities, reducing the cycle for developing new products, reducing risks, and generating options. Specifically, according to Taylor [70] and Jayaram and Ahire [71], cooperative relationships with suppliers may help improve speed. That is, the reduction of the supplier base leads to a huge simplification of the communication process and stronger interaction with suppliers, promoting a network of external contacts. This greater contact makes it possible for information to be spread more fluidly and achieves shorter cycle times. Consequently, we suggest the following.

Hypothesis 5. Supplier management is positively related to strategic flexibility.

\subsubsection{Process Management}

The idea behind this QM element is that organisations are sets of interlinked processes and that the improvement of processes is the foundation of performance improvements $[34,54,72]$. The management of processes in a QM environment encourages analysis of 
how processes currently work, establishing how they operate through working procedures and generally documented instructions, as well as creating mechanisms to promote the introduction of improvements in processes through the identification of performance indicators [48-50].

Taking into account this core idea of process management, if processes identify the organisational routines generated by the firm [51], the management and improvement of processes could lead to renovation of routines and, taking into account the contributions by Feldman and Pentland [45], allow routines to be a source of change rather than rigidity. In the same vein, Gilson et al. [65] note that creativity and the use of standardised work procedures can complement each other to benefit customer satisfaction. Standardised work practices may minimise ambiguity, avoid costly mistakes, and generate a more rapid response. For instance, a lack of standardised procedures may necessitate the search for new ways of working or experimentation with unproven approaches [65]. In the same line, as Flynn et al. [68] explain "documentation increases the flexibility of workers to perform a variety of operations, keeping the manufacturing process running smoothly, despite absenteeism and turnover." Precisely, as Dean and Bowen [34] and Hackman and Wageman [35] suggest, QM organisations should be a fruitful site for constant examination of technical and administrative processes in search of better methods; that is, QM promotes the research to meet standards more efficiently and to meet higher standards. Based on these arguments, we suggest the following.

Hypothesis 6. Process management is positively related to strategic flexibility.

\subsubsection{Customer Focus}

Customer focus is the key element in QM. According to Dean and Bowen [34], "the goal of satisfying customers is fundamental to QM and is expressed by the organization's attempt to design and deliver products and services that fulfil customer needs." It is pursued by fostering a close relationship with the customer in order to determine customer needs and obtain feedback about customer satisfaction and by incorporating this customer-related information into all activities of the organisation $[54,59,68]$.

In a QM initiative, organisational units maintain such close contact with the environment that they can adapt their performance strategies with minimum lag and perhaps even stay a step or two ahead of customers' wishes [35]. These knowledge and value-creating relationships with the customer are essential to sustain a lead in flexibility [29, page 62]. According to these authors, openness to customers provides the opportunity to understand them and to develop the business for them, so that the firm is able to anticipate customers' needs and wants and generate a variety of options to respond to customers' requirements in a timely and appropriate manner. In fact, customer-focused firms are more market-driven and thus possess superior capabilities with respect to customer satisfaction, adaptability, promotion, and product development [73]. These arguments lead us to posit the following.

Hypothesis 7. Customer focus is positively related to strategic flexibility.

\subsubsection{Quality Management}

So far we have analysed the contributions of specific QM elements; we now examine whether any positive covariation exists among QM elements that has a positive effect on 
strategic flexibility. QM is a multidimensional and integral approach that maintains strong consistency among all of its elements. In order for a QM initiative to be effective, all its constituent elements should be introduced at the same time, and issues of a more technical nature should be taken into account alongside social elements [36, 46, 55-57, 74, 75]. While technical issues include a more operational orientation, emphasising systems, obtaining data, and measurement, social elements include the more human and social side of business management. Authors subscribing to this view include Hill and Wilkinson [76], who consider that the most effective method of continuous improvement is to use the knowledge and skills of people whose task is to identify and implement process maps. McGee [77] also indicates that successful improvement initiatives manage to balance the needs of human systems with technical working processes in the implementation of a quality-based strategy. In addition, Mandal et al. [78] or Sun [79] indicate that QM's capability for generating long-term changes and creating value is rooted in the combination of all elements of QM.

The seven QM elements are, therefore, interrelated and mutually support one another. The fact that QM elements are correlated can be explained by the existence of a common factor that captures such covariation. This common factor is the QM factor, which is interpreted as the overall approach a firm adopts when it implements QM. In transferring this approach to the study of the relationship between QM and flexibility, we suggest that there is a consistency among QM elements and that their synchronised implementation will produce a systemic effect on strategic flexibility (see the multidimensional model in Figure 1(b)). Thus, we propose the following hypothesis.

Hypothesis 8. A positive covariation exists among QM elements that is positively related to strategic flexibility.

\section{Methodology}

\subsection{Sample}

To test the influence of QM elements on strategic flexibility, we used data from a survey on quality practices and performance designed by the authors. We use the Spanish National Information Service "ARDAN" to select the sample of firms. ARDAN provides information on more than 100,000 firms in Spain, which can be selected using different classification criteria such as sector, name, activity, size, or location.

In selecting firms, a random stratified sampling method was applied to avoid possible selection biases. Specifically, sector and size were used as stratification variables, and firms in the population were divided into groups (strata) according to these variables. First, division by sectors was made according to their SIC code and based on relevant criteria to evaluate the importance of quality in the sector. Service sectors were selected according to their degree of interaction and adjustment to the customer and varying labour intensity [80, 81]. Thus, in our study we included three service sectors: hotels (SIC 70.11), dealerships (SIC 55.11), and transport companies (SIC 42.13). The industrial sectors were selected on the basis of the degree of transaction complexity [82]. The sectors chosen were industrial ceramics (SIC 32.53), paints and glazes (SIC 28.51), and machinery (SIC 35.5). Second, following the European Union criteria (recommendation of European Commission 2003/361/EC), threesize segments were defined within each sector stratum: small (10-49 workers), medium-sized (50-249 workers), and large companies (250 or more workers). Finally, firms in the sample were chosen in proportion to the population of each stratum. Following this procedure, our 
final sample consisted of 453 firms, providing a good cross-section of the population in terms of sector and size.

Data was collected through personal interviews using a structured questionnaire that was administered to one key informant from each organisation who was deemed to be knowledgeable about the issues discussed in the survey. This informant was the quality manager in each organisation. All items were measured using a Likert scale ranging from 1 (very low score) to 7 (very high score). 453 complete questionnaires were used in our empirical research. According to ARDAN, the population was made up of 2,695 firms. Our sample size, therefore, implies a sample error of $\pm 3.28 \%(p=q=50 \%)$ for a $95 \%$ confidence level.

The distribution of firms by sector was $52 \%$ belonged to manufacturing sectors and $48 \%$ to service sectors. With regard to size, $50 \%$ were small firms, $42 \%$ medium-sized firms, and $8 \%$ large firms. The average number of employees per firm for the whole sample was 93.16 (standard deviation $=219.47$ ). The sample represented a good cross-section of Spanish firms in terms of sectors and size, with a predominance of small- and medium-sized firms.

\subsection{Measures}

\section{Quality Management}

Each QM element is measured as a latent construct, using a set of indicators reflecting the company's opinion on the use of different practices in the introduction of a QM initiative (see Figure 1 and Table 4). Various indicators were generated in order to capture the theoretical essence of each QM element. Most of the items were adopted from previous measurement instruments: Saraph et al. [83], Flynn et al. [68], Ahire et al. [59], and Samson and Terziovski [54] and supplemented by the general QM literature. The measurement instrument was then refined based on feedback from consultation with a group of $24 \mathrm{QM}$ experts (quality managers, academics, and consultants).

The QM factor is evaluated as a multidimensional latent construct made up of the seven QM elements. As Flynn et al. [68] and Dow et al. [84] stress, a basic assumption in the literature is the interdependence between the dimensions. This idea means QM is characterised by the common variance of all the practices. For this reason, QM is considered as a second-order factor, where the first-order factors are the seven dimensions. QM reflects, thus, the level firms achieved in the QM elements.

\section{Strategic Flexibility}

Strategic flexibility was measured as a latent construct with two dimensions, using the scale proposed by Roca et al. [85] (see Table 4), which follows recommendations from other studies about the use of the variety and speed dimensions (see $[7,17,18,86,87]$ ). These dimensions were chosen because they represented the most common measurement approach used in practice [87]. Moreover, following Nayyar and Bantel's [16] recommendations, for all the indicators managers were asked to evaluate the degree of strategic flexibility of their organisation in relation to competitors in their sector of activity.

\subsection{Statistical Procedure}

The estimation of the models was carried out using Structural Equation Modelling (SEM). All the analysis was carried out with the statistical software EQS 6.1 [88], using the maximum 
Table 4: Survey instrument.

Quality management elements

Reliability

Leadership items were developed following the criteria from Saraph et al. [83], Samson

and Terziovski [54], and Tarí et al. [38]

Management team participates in and supports continuous improvement process*

Management team encourages employees to help implement changes in the

organisation

Management team favours consensus on and trust in relevant objectives and future

c.r. $=0.822$

projects

Management team behaves in a way that allows employees to make their own decisions

Strategic planning items were adapted from Saraph et al. [83] and Samson and Terziovski [54]

Quality policies are revised and translated into a set of specific and measurable objectives

All members of the firm have a clear idea of what the firm's position in the market

$\alpha=0.810$

should be

c.r. $=0.843$

All members of the firm have objectives and a clear idea about what is expected of them

Every member in the organisation is aware of the organisational mission and objectives

Information and analysis items were adapted from Saraph et al. [83] and Ahire et al. [59]

Systematic measurement of quality and nonquality costs is carried out

Self-assessment processes take place on a regular basis

Benchmarking techniques are used to establish improvement standards and objectives

Employees have access to information about quality results

$\alpha=0.826$

c.r. $=0.829$

Information systems are in place to capture external information (about customers and markets)

Human resource management items were adapted from Saraph et al. [83], Flynn et al.

[55], and Ahire et al. [59]

People receive training in quality management

Teamwork systems are promoted

$\alpha=0.760$

Employee autonomy and participation is encouraged

c.r. $=0.770$

Employees learn skills and knowledge in the workplace itself as a result of measures made available to them for that purpose

Supplier management items were developed following the criteria from Saraph et al.

[83], Flynn et al. [55], Ahire et al. [59], and Sila and Ebrahimpour [40]

Quality agreements with suppliers are established*

Cooperation with suppliers provides the organisation with high-quality raw materials and resources

$\alpha=0.784$

Relationships with suppliers allow the organisation to have rapid access to

c.r. $=0.826$

information about new products and technology

The organisation has a high capacity for external cooperation

Process management items were developed following the criteria from Flynn et al. [55],

Samson and Terziovski [54], and Tarí et al. [38]

Systems of indicators are in place to revise changes in processes*

Work methods and organisational process are explicitly defined

$\alpha=0.828$

Quality manuals and organisational processes are periodically revised

c.r. $=0.837$

There is comprehensive documentation about work methods and organisational processes 
Table 4: Continued.

\begin{tabular}{ll}
\hline Quality management elements & Reliability \\
\hline $\begin{array}{l}\text { Customer orientation (CO) items were adapted from Ahire et al. [59] and Samson and } \\
\text { Terziovski [54] }\end{array}$ & \\
Standardised systems are in place to deal with customers complaints* & $\alpha=0.746$ \\
Customers' needs are taken into account when establishing strategy and objectives & c.r. =0.754 \\
Formal procedures (surveys, suggestions boxes, market research, commercial reports) & \\
are used to analyse possible changes in customers' needs and expectations & \\
Each area of the firm is given a report about the complaints and satisfaction of & \\
customers, both internal and external & $\alpha=0.920$ \\
\hline Strategic flexibility & C.r. $=0.920$ \\
\hline Competitive speed items from Roca et al. [85] & \\
We are capable of making rapid changes in design and introducing new & \\
products / services quickly & \\
The company designs new products / services very quickly & \\
We are capable of getting ahead of the competition in developing a new product or & \\
service & c.r. = $=0.669$ \\
\hline Competitive variety items from Roca et al. [85] & \\
We have a wide range of products and services & \\
Emphasis is placed on the development of innovative products / services & \\
Emphasis is placed on the development of new markets & \\
\hline *Items with an asterisk were eliminated in the CFA with the seven QM elements considered as correlated first-order factors.
\end{tabular}

likelihood estimation method. To protect our results from possible deviations from the normality assumption, all the reported chi-square values (as well as standard errors) correspond to Satorra and Bentler's [89] scaled goodness-of-fit test statistics.

\section{Results}

\subsection{Scale Validation}

To assess the dimensionality, reliability, and construct (convergent and discriminant) validity of the measurement scales, we followed the procedure usually recommended in the literature (e.g., $[59,90,91])$.

Scale dimensionality was assessed by executing a confirmatory factor analyses (CFA) for each QM element. Additionally, we conducted a single CFA with the seven QM elements considered as correlated first-order factors to check the dimensionality of the QM scale. We also estimated a single CFA model with two correlated first-order factors to analyse the properties of strategic flexibility scale. The Lagrange multiplier test was used to introduce successive modifications to those scales that presented poor goodness-of-fit indices. Only one parameter was altered in each iteration to avoid overmodifying the model [92]. As a result of this process, some items were deleted because they showed low reliability and/or presented significant cross-loadings (the eliminated items are marked with an asterisk in the Appendix section). The goodness-of-fit values for the CFA shown in Table 5 ensure an adequate fit of the measurement models and the hypothesised dimensionality.

Cronbach's Alpha [93] and Composite reliability (c.r.) [90] were used to assess the reliability of the measurement scales. Table 4 shows that both indices are above 0.7 in all 
Table 5: Dimensionality of the scales.

\begin{tabular}{lccccccc}
\hline Scale & No. of items & S-B $x^{2(a)}$ & $\mathrm{df}$ & $P$-value & BBNFI & CFI & RMSEA \\
\hline Leadership & 4 & 2.1142 & 2 & 0.34746 & 0.994 & 1.000 & 0.011 \\
Strategic planning & 4 & 0.2186 & 2 & 0.89644 & 0.999 & 1.000 & 0.000 \\
Information and analysis & 5 & 4.4109 & 5 & 0.49189 & 0.993 & 1.000 & 0.000 \\
Human resource management & 4 & 3.8266 & 2 & 0.14759 & 0.985 & 0.993 & 0.045 \\
Supplier management & 4 & 4.3637 & 2 & 0.11283 & 0.990 & 0.995 & 0.051 \\
Process management & 4 & 2.6880 & 2 & 0.26080 & 0.994 & 0.999 & 0.028 \\
Customer focus & 4 & 1.4122 & 2 & 0.49357 & 0.996 & 1.000 & 0.000 \\
Quality management & 25 & 478.8703 & 231 & 0.00000 & 0.922 & 0.935 & 0.050 \\
Strategic flexibility & 6 & $14.037^{(\mathrm{b})}$ & 8 & 0.081 & 0.980 & 0.991 & 0.041 \\
\hline
\end{tabular}

(a) The Satorra-Bentler scaled chi-square [89].

(b) Since each strategic flexibility dimension (speed and variety) has fewer than four indicators, to avoid negative degrees of freedom, a pooled measurement model was executed with indicators loading on the corresponding dimension [91].

measurement scales, except for "variety", which showed reliability coefficients slightly below the threshold. Nevertheless, values around 0.6 could be considered acceptable [94, 95], and consequently we decided to retain the value to avoid affecting the content validity of the model.

To assess convergent validity, we used the Bentler-Bonett normed fit index (BBNFI) [96]. Such goodness-of-fit index measures the improvement in fit of the proposed model over the "independence" or null model (i.e., a model that assumes that all variables are uncorrelated). In all scales, Table 5 shows a BBNFI greater than .90 , indicating a strong convergent validity [59].

To test the discriminant validity of the measurement scale, we conducted a "pairwise test" [97]. For each pair of factors, we conducted a "pairwise test" to test whether a CFA with two factors fits the data significantly better than a single-factor model; that is, whether each factor really does represent a different concept. A statistically significant difference between the chi-squared values for the two models (degree of freedom $=1$ ) will enable us to support the existence of discriminant validity. The scaled chi-square difference values [98] for all pairs were found to be statistically significant at $5 \%$ level (and hence they are not presented), providing evidence of the existence of discriminant validity.

Table 6 shows the mean, standard deviation, and correlations of the 9 unidimensional scales identified in the scale validation process. All correlations were positive and significantly different from zero, a result that is not surprising in the case of the QM elements since they form part of the integrated approach of QM [99].

\subsection{Results for the Structural Models}

To test our hypotheses, we estimated the structural models shown in Figure 1. The multivariate model (Figure 1(a)) allows us to test the influence of each QM element on flexibility (H1 to H7). The multidimensional model (Figure 1(b)) tests for the existence of a systemic effect of QM elements when they are brought together in a QM initiative (H8). To reduce both the number of parameters to be estimated and the complexity of the models, the seven factors referring to QM elements included in the structural models were measured by a single indicator obtained by computing the mean of the measures for each one [100]. Table 7 
Table 6: Means, standard deviations, correlations.

\begin{tabular}{|c|c|c|c|c|c|c|c|c|c|}
\hline & (1) & $(2)$ & (3) & (4) & (5) & $(6)$ & (7) & $(8)$ & (9) \\
\hline Leadership (1) & 1 & & & & & & & & \\
\hline Strategic planning (2) & 0.5270 & 1 & & & & & & & \\
\hline Information and analysis (3) & 0.4598 & 0.5726 & 1 & & & & & & \\
\hline Human resource management (4) & 0.5239 & 0.6193 & 0.7403 & 1 & & & & & \\
\hline Supplier management (5) & 0.3632 & 0.4162 & 0.4944 & 0.5047 & 1 & & & & \\
\hline Process management (6) & 0.3432 & 0.3716 & 0.6761 & 0.5358 & 0.3945 & 1 & & & \\
\hline Customer focus (7) & 0.3725 & 0.4494 & 0.6363 & 0.6444 & 0.3884 & 0.5163 & 1 & & \\
\hline Speed (8) & 0.3771 & 0.3949 & 0.4988 & 0.4957 & 0.5386 & 0.3967 & 0.3756 & 1 & \\
\hline Variety (9) & 0.3338 & 0.3095 & 0.4389 & 0.3602 & 0.4302 & 0.4236 & 0.3027 & 0.5167 & 1 \\
\hline Mean & 5.708 & 5.554 & 4.876 & 5.271 & 5.212 & 5.385 & 5.074 & 5.421 & 5.493 \\
\hline SD & 1.058 & 1.209 & 1.460 & 1.185 & 1.238 & 1.497 & 1.406 & 1.260 & 1.043 \\
\hline
\end{tabular}

Table 7: Goodness-of-fit indices for the structural models.

\begin{tabular}{lcccccc}
\hline Model & S-B $x^{2}$ & df & $P$-value & BBNFI & CFI & RMSEA \\
\hline Multivariate model & 59,7979 & 42 & 0.0366 & 0.971 & 0.991 & 0.031 \\
Multidimensional model & 159,1802 & 62 & 0.000 & 0.924 & 0.952 & 0.059 \\
\hline
\end{tabular}

shows the goodness-of-fit indices for the two models. All the indices show the adequacy of the models for the analysed data.

Table 8 shows the influence of QM elements on strategic flexibility. Only four structural parameters are statistically significant. Consequently, our results support the influence of leadership (H1), information and analysis (H3), supplier management (H5), and process management (H6) on strategic flexibility. However, the specific effect of strategic planning, strategic human resource management, and customer focus is not evidenced. Consequently $\mathrm{H} 2, \mathrm{H} 4$, and $\mathrm{H} 7$ are not supported. Not all QM elements have a significant effect in improving strategic flexibility.

The multidimensional model of QM allows us to test the effect of the communality among all QM elements (represented by the second-order QM factor) on strategic flexibility (see Table 9).

The value of the regression parameter (0.748) attests that QM exerts a positive and statistically significant effect on strategic flexibility, confirming H8. The value of the coefficient of determination $\left(R^{2}=0.560\right)$ indicates that QM explains more than $50 \%$ of the variance of strategic flexibility. These results lend support to the influence of QM initiatives on flexibility. The multidimensional structure of the model presented means it is not enough merely to ensure acceptable levels of only some QM elements.

\section{Discussion}

\subsection{Significant Relationships in the Multivariate Model}

When we considered QM elements in a multivariate model, our empirical research demonstrated that only four QM elements (strategic leadership, information and analysis, supplier management, and process management) contribute positively to strategic flexibility. 
Table 8: Results for the multivariate model.

\begin{tabular}{lccc}
\hline Structural effects & $\begin{array}{c}\text { Standardised } \\
\text { parameter } \\
\text { estimates }\end{array}$ & $\begin{array}{c}\text { Standard } \\
\text { errors }\end{array}$ & Z test \\
\hline Leadership $\rightarrow$ strategic flexibility (H1) & $0.154^{*}$ & 0.070 & 2.094 \\
Strategic Planning $\rightarrow$ strategic flexibility (H2) & 0.033 & 0.054 & 0.516 \\
Information and analysis $\rightarrow$ strategic flexibility (H3) & $0.201^{*}$ & 0.061 & 2.269 \\
Human Resource Management $\rightarrow$ strategic flexibility (H4) & 0.075 & 0.069 & 0.921 \\
Supplier Management $\rightarrow$ strategic flexibility (H5) & $0.404^{* *}$ & 0.057 & 5.785 \\
Process Management $\rightarrow$ strategic flexibility (H6) & $0.145^{*}$ & 0.045 & 2.183 \\
Customer Orientation $\rightarrow$ strategic flexibility (H7) & -0.008 & 0.039 & -0.141 \\
\hline
\end{tabular}

${ }^{* *} P<0.05$

${ }^{* *} P<0.01$.

Table 9: Results for the multidimensional model.

\begin{tabular}{lcccc}
\hline Effect & Standardised parameter estimates & Standard errors & Z test & $R^{2}$ \\
\hline Item-factor loadings & & & & \\
$\mathrm{QM} \rightarrow$ leadership & $0.586^{* *}$ & 0.055 & 11.172 & 0.344 \\
$\mathrm{QM} \rightarrow$ strategic planning & $0.683^{* *}$ & 0.058 & 14.210 & 0.466 \\
$\mathrm{QM} \rightarrow$ information and analysis & $0.872^{* *}$ & 0.051 & 24.7660 .761 \\
$\mathrm{QM} \rightarrow$ human resource management & $0.860^{* *}$ & 0.048 & 20.8730 .740 \\
$\mathrm{QM} \rightarrow$ supplier management & $0.599^{* *}$ & 0.058 & 12.767 & 0.359 \\
$\mathrm{QM} \rightarrow$ process management & $0.686^{* *}$ & 0.066 & 15.369 & 0.470 \\
$\mathrm{QM} \rightarrow$ customer orientation & $0.715^{* *}$ & 0.058 & 17.389 & 0.511 \\
Structural Effect & & & & \\
$\mathrm{QM} \rightarrow$ strategic flexibility $(\mathrm{H} 8)$ & $0.748^{* *}$ & 0.068 & 9.251 & 0.560 \\
\hline
\end{tabular}

Nevertheless, other QM elements such as strategic planning, human resource management, and customer focus do not seem to be inductors of flexibility on their own.

Our results indicate that leadership characterising QM allows members of a team to integrate and mobilise and makes it easier for employees to accept proposed changes, which in turn facilitates flexibility, as stated by Hitt et al. [6]. In the same way, the acquisition, analysis and dissemination of information that enables fact-based management is revelled as an important element to improve strategic flexibility supporting Hatum and Pettigrew's [58] or Celuch et al.'s [32] view.

In relations to process management, this study notes some ideas concerning a controversial issue in the literature-the consideration of whether QM is an initiative that promotes dynamism and flexibility or whether it involves excessive formalisation and imposition of routines within the organisation. We are aware that some authors [101,102] consider that various actions developed in a QM initiative, such as the explicit definition of tasks and responsibilities or the drawing up of procedures to promote efficiency improvements, can have a perverse effect on flexibility. From their point of view, although process management activities are employed to help organisations adapt, because these practices increase inertia and limit variation creation, they may instead impede adaptation. Process standardisation might induce complacency with established routines so that ideas and actions that deviate from the routines may be ignored [8]. They might thus act as a barrier to strategic flexibility since ideas and actions that deviate from the current routines will not be considered as 
legitimate. However, the results of our study support the alternative view that the establishment of working procedures promotes the achievement of high levels of flexibility, as indicated by Adler and Borys [103] and MacDuffie [104]. The establishment of working procedures and the reduction of deviations in processes are compatible with the creativity and the change necessary to improve flexibility. Following Hackman and Wageman [35], loss of employee autonomy and the chance to be creative that go hand in hand with standardisation and process controls are compensated by greater collective autonomy and creativity in how tasks are designed in the first place.

Finally, the positive and significant association between supplier management and strategic flexibility indicates the relevance of partnership with suppliers and points to the need for an integrated view of flexibility in the entire supply chain as suggested by Lummus et al. [105].

\subsection{Nonsignificant Relationships in the Multivariate Model}

With regard to other QM elements, our empirical research support the argument that strategic planning in QM may lead to establishing planning process routines that may entail rigidity instead of flexibility, holding the discourse by Dibrell et al. [106]. QM literature strongly emphasises strategy deployment through approaches such as policy deployment. As Dean and Bowen [34] highlight, in policy deployment top managers develop strategic priorities annually that are then deployed throughout the organisation, with progressively more detailed plans for achieving them established at each level. As Dibrell et al. [106, page 27] point out, routinisation often limits variation, and firms with more specific strategic planning objectives and implementation plans will have lower capabilities to recognise and respond to changes in customer needs. "Hence, a long-range planning process may act as a constraint on a firm to adjust the content of its strategy to changes in the competitive environment" [106, page 28].

Human resource management in its own is not evidenced to enable strategic flexibility, so the ideas by Peccei and Rosenthal [67], Hitt et al. [6], or Prastacos et al. [29] could not be confirmed. One possible explanation for this nonsignificant effect is the existence of other intermediate variables that we did not consider in the multivariate model. For instance, a variable of interest that would explain the effect of HRM on strategic flexibility could be employee flexibility, and it would be interesting to be introduced into the model as a mediating variable.

With regard to customer focus, our results seem to support Beverland [107] or Perry and Shao [108] who find that customer orientation does not necessarily result in customer responsiveness and flexibility. These authors argue that relational commitment to customers may have a paradoxical role: relationships may trigger adaptation while at the same time leading to a reactive mindset. Deep relationships with customers may cause inertia by jeopardising the firm's chances of keeping up with emerging trends in the market. A strong customer orientation must, therefore, be complemented by market-based ties in order to keep the firm's mindset fresh.

\subsection{Multidimensional Model}

When we consider QM elements as a multidimensional model, the empirical results show that the communality between the QM elements is what improves strategic flexibility. In this 
case, the results of our study broadly follow other previous studies that also find a positive relationship between the introduction of a QM initiative and flexibility, such as those by González and Dale [12], Gómez and Verdú [14], or Merino [13]. Our research complements these studies and indicates that the effect on flexibility of QM elements appears because there is an underlying orientation toward QM in the company. Companies that are not fully involved in an integral QM initiative, that is, a piecemeal implementation of QM elements, will not be able to capitalise on all the potential of QM in terms of its effect on flexibility.

\section{Conclusions}

\subsection{Academic Implications}

This paper has allowed us to look at QM elements from the view of strategic flexibility. We have dealt with the influence QM has on an interesting variable-strategic flexibilitythat has not traditionally received a great deal of research attention because much of the literature focuses on analysing the final influence of $\mathrm{QM}$ on organisational results. In this sense, we complement previous QM literature [11, 14, 15, 35, 43] that suggests a certain analogy between QM and strategic flexibility, by discussing the degree to which QM elements may be flexibility inductors.

Our contribution could be synthesised on the theoretical discussion of how the implementation of each QM element may or not generate flexibility and on the empirical analysis of which QM elements could be considered true flexibility-inducing mechanisms. On the one hand, considering the individual effects of QM elements on flexibility, our results show that leadership, information and analysis, supplier management, and process management are related positively to strategic flexibility. These elements might be considered equivalent to actions referred to in the literature as strategic flexibility enablers (see $[6,8,29]$ ). Nevertheless, other elements like strategic planning, human resource management, and customer orientation do not influence strategic flexibility on their own. On the other hand, when we take into account the communality among all the QM elements, our results indicate that strategic flexibility is influenced by the QM factor, which involves all the QM elements. The multidimensional structure of QM means that ensuring acceptable levels of only some elements is not enough on its own. Rather, acceptable levels must be reached in all elements to some degree, because of their complementary nature. It is the joint variance of the elements characteristic of QM that is responsible for their positive effect on strategic flexibility. Involvement in a QM strategy requires the adoption of a systemic approach.

These findings have implications for future research in QM, as they suggest the existence of some core and instrumental QM elements, similarly to the QM groups advocated by Flynn et al. [55]. Core QM elements would be those that have a direct influence on strategic flexibility, and instrumental elements would be those that support and facilitate the effective use of core elements but have not a direct effect on strategic flexibility. A further academic implication concerns the extent to which QM could be taken as a multivariate or as a multidimensional model. Further empirical work should consider the different results that could be obtained from each modelling option.

Finally, the results of this study are in line with the cumulative literature [109-112] on manufacturing suggesting that different generic capabilities are cumulative and not the result of compromises and tradeoffs. Under this perspective, the consideration of QM as an important organisational capability $[51,113]$ is now complemented by its crucial role in the development of another essential organisational capability: strategic flexibility. 


\subsection{Managerial Implications}

Practitioners may be aware of the whole range of potential effects of QM. The results of the study suggest some criteria for guiding efforts to improve firm's capabilities to adapt to change. We present actions managers can take to improve the level of strategic flexibility, linked to QM elements. This means that companies can take advantage of the introduction of this kind of initiative to improve their business processes without worrying about whether this is going to mean a loss of flexibility. On the contrary, this study suggests that QM organisations are well equipped to adjust to the requirements of the environment as long as they understand QM as an integral initiative and do not introduce it in a piecemeal fashion. Our results suggest that managers must encourage the joint application of the various elements linked to $\mathrm{QM}$, by trying to adopt a holistic approach and not ignoring any of the associated QM elements.

Following the conclusions by Prajogo and Sohal [114], our paper also points out that organisations should not reject a QM initiative even though quality is not an important competitive weapon in their situation. The organisational conditions that QM elements create can further help to develop other important organisational capabilities such as strategic flexibility.

\subsection{Limitations and Future Research}

We recognise some limitations to our work that we must take into consideration and that point toward possible future studies. In our study we obtained information only from a single member of the management team. We believe that future research could incorporate other sources of information in order to improve the validity of the information obtained. We did not jointly analyse the final effect that QM can have on flexibility and on results. Future studies should attempt to analyse in greater depth the relationship between QM, flexibility, and results, along the lines of a study carried out by Gómez and Verdú [14]. These authors conclude that companies introducing a QM initiative improve their flexibility, but this does not translate into improved results. Kara et al. [33] take a similar approach and conclude that the type of environment has a moderating effect on the relationship between flexibility and results.

Finally, following the hierarchical view of flexibility highlighted by authors like Koste and Malhotra [20], an interesting line of study would be the possible direct effect QM has on types of flexibility at the lower level of the hierarchy and the indirect effect on strategic flexibility.

\section{References}

[1] S. B Sitkin, K. Sutcliffe, and R. G. Schroeder, "Distinguishing control from learning in total quality management: a contingency perspective," Academy of Management Review, vol. 19, no. 3, pp. 537-564, 1994.

[2] T. J. Douglas and W. Q. Judge, "Total quality management implementation and competitive advantage: the role of structural control and exploration," Academy of Management Journal, vol. 44, no. 1, pp. 158-169, 2001.

[3] D. I. Prajogo and A. S. Sohal, "The relationship between organization strategy, total quality management (TQM), and organization performance-the mediating role of TQM," European Journal of Operational Research, vol. 168, no. 1, pp. 35-50, 2006. 
[4] D. M. Upton, "What really makes factories flexible," Harvard Business Review, vol. 73, no. 4, pp. 74-84, 1995.

[5] H. W. Volberda, Building the Flexible Firm. How to Remain Competitive, Oxford University Press, New York, NY, USA, 1998.

[6] M. A. Hitt, B. W. Keats, and S. M. DeMarie, "Navigating in the new competitive landscape: building strategic flexibility and competitive advantage in the 21st century," Academy of Management Executive, vol. 12, no. 4, pp. 22-42, 1998.

[7] N. Worren, K. Moore, and P. Cardona, "Modularity, strategic flexibility, and firm performance: a study of the home appliance industry," Strategic Management Journal, vol. 23, no. 12, pp. 1123-1140, 2002.

[8] K. Shimizu and M. A. Hitt, "Strategic flexibility: organizational preparedness to reverse ineffective strategic decisions," Academy of Management Executive, vol. 18, no. 4, pp. 44-59, 2004.

[9] A. J. Verdú, J. M. Gómez, and J. Lloréns, "Exploring managerial flexibility: determinants and performance implications," Industrial Management $\mathcal{E}$ Data Systems, vol. 108, no. 1, pp. 70-86, 2008.

[10] E. S. Bernardes and M. D. Hanna, "A theoretical review of flexibility, agility and responsiveness in the operations management literature: toward a conceptual definition of customer responsiveness," International Journal of Operations and Production Management, vol. 29, no. 1, pp. 30-53, 2009.

[11] T. Savolainen, "Leadership strategies for gaining business excellence through total quality management: a Finnish case study," Total Quality Management, vol. 11, no. 2, pp. 211-226, 2000.

[12] J. González and B. Dale, "Supplier quality and reliability assurance practices in the Spanish auto components industry: a study of implementation issues," European Journal of Purchasing and Supply Management, vol. 7, no. 3, pp. 187-196, 2001.

[13] J. Merino, "Quality management practices and operational performance: empirical evidence for Spanish industry," International Journal of Production Research, vol. 41, no. 12, pp. 2763-2786, 2003.

[14] J. M. Gómez and A. J. Verdú, "TQM, structural and strategic flexibility and performance: an empirical research study," Total Quality Management and Business Excellence, vol. 16, no. 7, pp. 841860, 2005.

[15] L. Gutiérrez and V. Pérez, "Managerial networks and strategic flexibility: a QM perspective," Industrial Management \& Data Systems, vol. 110, no. 8, pp. 1192-1214, 2010.

[16] P. R. Nayyar and J. A. Bantel, “Competitive agility: a source of competitive advantage based on speed and variety," Advances in Strategic Management, vol. 10, pp. 193-222, 1994.

[17] H. W. Volberda, "Toward the flexible form: how to remain vital in hypercompetitive environmentss," Organization Science, vol. 7, no. 4, pp. 359-374, 1996.

[18] H. W. Volberda, “Building flexible organizations for fast-moving markets," Long Range Planning, vol. 30, no. 2, pp. 169-183, 1997.

[19] D. Narasimhan and A. Das, "An empirical investigation of the contribution of strategic sourcing to manufacturing flexibilities and performance," Decision Sciences, vol. 30, no. 3, pp. 683-718, 1999.

[20] L. Koste and M. Malhotra, "A Theoretical framework for analyzing the dimensions of manufacturing flexibility," Journal of Operations Management, vol. 18, no. 1, pp. 75-93, 1999.

[21] J. L. Johnson, R. P. W. Lee, A. Saini, and B. Grohmann, "Market-focused strategic flexibility: conceptual advances and an integrative model," Journal of the Academy of Marketing Science, vol. 31, no. 1, pp. 74-89, 2003.

[22] A. De Toni and S. Tonchia, "Definitions and linkages between operational and strategic flexibilities," Omega, vol. 33, no. 6, pp. 525-540, 2005.

[23] N. Slack, "The flexibility of manufacturing systems," International Journal of Operations and Production Management, vol. 17, no. 4, pp. 35-45, 1987.

[24] J. S. Evans, "Strategic flexibility for high technology manoeuvres: a conceptual framework," Journal of Management Studies, vol. 28, no. 1, pp. 69-89, 1991.

[25] D. A. Aaker and B. Mascarenhas, "The need for strategic flexibility," Journal of Business Strategy, vol. 5, pp. 74-78, 1984.

[26] J. Baker, "Agility and flexibility: what's the difference?" Cranfield University School of Management Working Paper Series, SWP 5/96, 1996.

[27] H. M. Judi, R. Beach, and A.P. Muhlemann, “Defining manufacturing flexibility: a research prerequisite," University of Bradford School of Management, Working Paper, no. 04/38, 2004. 
[28] T. K. Das and B. Elango, "Managing strategic flexibility: key to effective performance," Journal of General Management, vol. 20, pp. 60-75, 1995.

[29] G. Prastacos, K. Söderquist, Y. Spanos, and L. Van Wassenhove, "An integrated framework for managing change in the new competitive landscape," European Management Journal, vol. 20, no. 1, pp. 55-71, 2002.

[30] P. J. Liebeskind, A. L. Oliver, L. Zucker, and M. Brewer, "Social networks, learning, and flexibility: sourcing scientific knowledge in new biotechnology firms," Organization Science, vol. 7, no. 4, pp. 428-443, 1996.

[31] M. J. Zhang, "Information systems, strategic flexibility and firm performance: an empirical investigation," Journal of Engineering and Technology Management, vol. 22, no. 3, pp. 163-184, 2005.

[32] K. Celuch, G. B. Murphy, and S. K. Callaway, "More bang for your buck: small firms and the importance of aligned information technology capabilities and strategic flexibility," Journal of High Technology Management Research, vol. 17, no. 2, pp. 187-197, 2007.

[33] S. Kara, B. Kayis, and S. O'Kane, "The role of human factors in flexibility management: a survey," Human Factors and Ergonomics In Manufacturing, vol. 12, no. 1, pp. 75-119, 2002.

[34] J. W. Dean and D. E. Bowen, "Management theory and total quality: improving research and practice through theory development," Academy of Management Review, vol. 19, no. 3, pp. 392-418, 1994.

[35] J. R. Hackman and R. Wageman, "Total quality management: empirical, conceptual, and practical issues," Administrative Science Quarterly, vol. 40, pp. 309-342, 1995.

[36] B. G. Dale, Managing Quality, Blackwell, Oxford, UK, 4th edition, 2003.

[37] H. Eriksson and R. Garvare, "Organisational performance improvement through quality award process participation," International Journal of Quality $\mathcal{E}$ Reliability Management, vol. 22, no. 9, pp. 894-912, 2005.

[38] J. J. Tarí, J. F. Molina, and J. L. Castejón, "The relationship between quality management practices and their effects on quality outcomes," European Journal of Operational Research, vol. 183, no. 2, pp. 483-501, 2007.

[39] I. Sila, "Examining the effects of contextual factors on TQM and performance through the lens of organizational theories: an empirical study," Journal of Operations Management, vol. 25, no. 1, pp. 83-109, 2007.

[40] I. Sila and M. Ebrahimpour, "Critical linkages among TQM factors and business results," International Journal of Operations and Production Management, vol. 25, no. 11, pp. 1123-1155, 2005.

[41] S. Curkovic, S. Melnyk, R. Calantone, and R. Handfield, "Validating the Malcolm Baldrige National Quality Award framework through structural equation modeling," International Journal of Production Research, vol. 38, no. 4, pp. 765-791, 2000.

[42] J. C. Bou, A. B. Escrig, V. Roca, and I. Beltrán-Martín, "An empirical assessment of the EFQM excellence model: evaluation as a TQM framework relative to the MBNQA model," Journal of Operations Management, vol. 27, no. 1, pp. 1-22, 2009.

[43] S. Hill, "Why Quality Circles failed but Total Quality management might succeed," British Journal of Industrial Relations, vol. 19, no. 4, pp. 541-69, 1991.

[44] M. A. Youssef, J. Boyd, and E. Williams, "The impact of total quality management on firms' responsiveness: an empirical analysis," Total Quality Management, vol. 7, no. 1, pp. 127-144, 1996.

[45] M. S. Feldman and B. T. Pentland, "Reconceptualizing organizational routines as a source of flexibility and change," Administrative Science Quarterly, vol. 48, no. 1, pp. 94-118, 2003.

[46] D. I. Prajogo and A. S. Sohal, "The multidimensionality of TQM practices in determining quality and innovation performance-an empirical examination," Technovation, vol. 24, no. 6, pp. 443-453, 2004.

[47] D. T. Hoang, B. Igel, and T. Laosirihongthong, "The impact of total quality management on innovation: findings from a developing country," International Journal of Quality E Reliability Management, vol. 23, no. 9, pp. 1092-1117, 2006.

[48] D. Y. Kim, V. Kumar, and S. A. Murphy, "European foundation for quality management business excellence model: an integrative review and research agenda," International Journal of Quality $\mathcal{E}$ Reliability Management, vol. 27, no. 6, pp. 684-701, 2010.

[49] J. C. Anderson, M. Rungtusanatham, and R. G. Schroeder, "A theory of quality management underlying the Deming management method," Academy of Management Review, vol. 19, no. 3, pp. 472-509, 1994.

[50] T. C. Powell, "Total Quality Management as competitive advantage: a review and empirical study," Strategic Management Journal, vol. 16, pp. 15-37, 1995.

[51] J. I. Castresana and R. Fernández, "Theoretical foundation of the EFQM model: the resource-based view," Total Quality Management and Business Excellence, vol. 16, no. 1, pp. 31-55, 2005. 
[52] V. M. Tummala and C. L. Tang, "Strategic quality management, Malcolm Baldrige and European quality awards and ISO 9000 certification," International Journal of Quality E Reliability Management, vol. 13 , no. 4, pp. 8-38, 1996.

[53] P. Staggs, "Strategic planning as a total quality management critical success factor," Journal of Organizational Leadership, vol. 1, no. 1, pp. 5-17, 1999.

[54] D. Samson and M. Terziovski, "Relationship between total quality management practices and operational performance," Journal of Operations Management, vol. 17, no. 4, pp. 393-409, 1999.

[55] B. B. Flynn and R. G. Sakakiraba S. Schroeder, “Determinants of quality performance in high and low quality plants," Quality Management Journal, vol. 2, no. 2, pp. 8-25, 1995.

[56] H. Kaynak, "The relationship between total quality management practices and their effects on firm performance," Journal of Operations Management, vol. 21, no. 4, pp. 405-435, 2003.

[57] X. Zu, "Infrastructure and core quality management practices: how do they affect quality?" International Journal of Quality \& Reliability Management, vol. 26, no. 2, pp. 129-149, 2009.

[58] A. Hatum and A. M. Pettigrew, "Determinants of organizational flexibility: a study in an emerging economy," British Journal of Management, vol. 17, no. 2, pp. 115-137, 2006.

[59] S. L. Ahire, D. Y. Golhar, and M. A. Waller, "Development and validation of TQM implementation constructs," Decision Sciences, vol. 27, no. 1, pp. 23-53, 1996.

[60] A. Bayo and J. Merino, "Quality management and high performance work practices: do they coexist?" International Journal of Production Economics, vol. 73, no. 3, pp. 251-259, 2001.

[61] M. A. Youndt, S. A. Snell, J. W. Dean, and D. P. Lepak, "Human resource management, manufacturing strategy, and firm performance," Academy of Management Journal, vol. 39, no. 4, pp. 836-866, 1996.

[62] C. Chadwick and P. Cappelli, "The performance effects of competing human resource systems," Working paper, 2000.

[63] H. M. Judi, R. Beach, and A. P. Muhlemann, "The contribution of total quality management and business process re-engineering to the achievement of operational flexibility in an environment influenced by national culture," in Advances in Manufacturing Technology, D. T. Pahm, et al., Ed., Professional Engineering, 2001.

[64] K. L Sim and A. P. Curatola, "Time-based-competition," International Journal of Quality E Reliability Management, vol. 17, no. 7, pp. 659-674, 1999.

[65] L. L. Gilson, J. Mathieu, C. E. Shalley, and T. M. Ruddy, “Creativity and standardization: complementary or conflicting drivers of team effectiveness?" Academy of Management Journal, vol. 48, no. 3, pp. 521-531, 2005.

[66] R. Grant, R. Shani, and R. Krishnan, "TQM's challenge to management theory and practice," Sloan Management Review, vol. 35, no. 2, pp. 25-35, 1994.

[67] R. Peccei and P. Rosenthal, "The antecedents of employee commitment to customer service: evidence from a UK service context," International Journal of Human Resource Management, vol. 8, no. 1, pp. 6686, 1997.

[68] B. B. Flynn, R. G. Schroeder, and S. Sakakibara, "A framework for quality management research and an associated measurement instrument," Journal of Operations Management, vol. 11, no. 4, pp. 339-366, 1994.

[69] H. Bahrami, "The emerging flexible organization: perspectives from Silicon Valley," California Management Review, vol. 34, no. 4, pp. 33-52, 1992.

[70] G. Taylor, "Parallel processing: a design principle for system-wide total quality management," Management International Review, vol. 33, pp. 99-109, 1993.

[71] J. Jayaram and S. Ahire, "Impact of operations management practices on quality and time-based performance," International Journal of Quality E Reliability Management, vol. 15, no. 2, pp. 192-204, 1998.

[72] W. E. Deming, Out of the Crisis. Quality, Productivity and Competitive Position, Cambride University Press, 1986.

[73] D. W. Vorhies, M. Harker, and C. P. Rao, "The capabilities and performance advantages of marketdriven firms," European Journal of Marketing, vol. 33, no. 11-12, pp. 1171-1202, 1999.

[74] J. Yong and A. Wilkinson, "Rethinking total quality management," Total Quality Management, vol. 12, no. 2, pp. 247-258, 2001.

[75] W. G. Lewis, K. F. Pun, and T. R. M. Lalla, "Empirical investigation of the hard and soft criteria of TQM in ISO 9001 certified small and medium-sized enterprises," International Journal of Quality $\mathcal{E}$ Reliability Management, vol. 23, no. 8, pp. 964-985, 2006.

[76] S. Hill and A. Wilkinson, "In search of TQM," Employee Relations, vol. 17, no. 3, pp. 8-26, 1995. 
[77] E. C. McGee, "The convergence of total quality and work design," Journal of Quality E Participation, vol. 16, no. 2, pp. 90-96, 1993.

[78] P. Mandal, A. Howell, and A. S. Sohal, "A systemic approach to quality improvements: the interactions between the technical, human and quality systems," Total Quality Management, vol. 9, no. 1, pp. 79-100, 1998.

[79] H. Sun, "Diffusion and contribution of total quality management: an empirical study in Norway," Total Quality Management, vol. 10, no. 6, pp. 901-914, 1999.

[80] J. A. Dotchin and J. S. Oakland, "Total quality management in services. Part 1: understanding and classifying services," International Journal of Quality E Reliability Management, vol. 11, no. 3, pp. 9-26, 1994.

[81] R. Silvestro, "Positioning services along the volume-variety diagonal: the contingencies of service design, control and improvement," International Journal of Operations and Production Management, vol. 19, no. 4, pp. 399-421, 1999.

[82] J. A. De Vasconcellos and D. C. Hambrick, "Key success factors: test a general theory in the mature industrial-product sector," Strategic Management Journal, vol. 10, no. 4, pp. 367-383, 1989.

[83] J. Saraph, P. G. Benson, and R. Schroeder, "An Instrument for Measuring the Critical Factors of Quality Management," Decision Sciences, vol. 20, pp. 810-829, 1989.

[84] D. Dow, D. Samson, and S. Ford, "Exploding the myth: do all quality management practices contribute to superior quality performance?" Production and Operations Management, vol. 8, no. 1, pp. 1-27, 1999.

[85] V. Roca, A. B. Escrig, I. Beltrán, and J. C. Bou, "Strategic flexibility as a moderator of the relationship between commitment to employees and performance in service firms," International Journal of Human Resource Management, vol. 16, no. 11, pp. 2075-2095, 2005.

[86] A. Martínez, M. J. Vela, M. Pérez, and P. De Luis, "Flexibilidad e innovación: el efecto moderador de la cooperación," Revista Europea de Dirección y Economía de la Empresa, vol. 16, no. 4, pp. 69-88, 2007.

[87] H. M. Judi and R. Beach, "The structure of manufacturing flexibility: comparison between UK and Malaysian manufacturing firms," Journal of Applied Sciences, vol. 8, no. 19, pp. 3340-3350, 2008.

[88] P. M. Bentler, "EQS structural equations program manual," Multivariate Software, Encino, Calif, USA, 2006.

[89] A. Satorra and P. M. Bentler, "Corrections to test statistics and standard errors in covariance structure analysis," in Latent Variables Analysis: Applications for Developmental Research, A. von Eye and C. C. Clogg, Eds., pp. 399-419, Sage, Thousand Oaks, Calif, USA, 1994.

[90] C. Fornell and D. F. Larcker, "Evaluating structural equation models with unobservable variables and measurement error," Journal of Marketing Research, vol. 18, no. 1, pp. 39-50, 1981.

[91] S. L. Ahire and T. Ravichandran, "An innovation diffusion model of TQM implementation," IEEE Transactions on Engineering Management, vol. 48, no. 4, pp. 445-464, 2001.

[92] K. G. Jöreskog and D. Sörbom, LISREL 8: User's Reference Guide, Scientific Software, Chicago, Ill, USA, 1996.

[93] L. J. Cronbach, "Coefficient alpha and the internal structure of tests," Psychometrika, vol. 16, no. 3, pp. 297-334, 1951.

[94] J. F. Hair, R. E. Anderson, R. L. Tatham, and W. C. Black, Multivariate Data Analysis, Prentice-Hall, Upper Saddle River, NJ, USA, 5th edition, 1998.

[95] K. K. Boyer and M. Pagell, "Measurement issues in empirical research: improving measures of operations strategy and advanced manufacturing technology," Journal of Operations Management, vol. 18, no. 3, pp. 361-374, 2000.

[96] P. M. Bentler and D. G. Bonett, "Significance tests and goodness of fit in the analysis of covariance structures," Psychological Bulletin, vol. 88, no. 3, pp. 588-606, 1980.

[97] R. P. Bagozzi and L. W. Phillips, "Representing and testing organizational theories: a holistic construal," Administrative Science Quarterly, vol. 27, pp. 459-489, 1982.

[98] A. Satorra and P. M. Bentler, "A scaled difference chi-square test statistic for moment structure analysis," Psychometrika, vol. 66, no. 4, pp. 507-514, 2001.

[99] B. B. Flynn and B. Saladin, "Further evidence on the validity of the theoretical models underlying the Baldrige criteria," Journal of Operations Management, vol. 19, no. 6, pp. 617-652, 2001.

[100] R. P. Bagozzi and J. R. Edwards, "A general approach for representing constructs in organizational research," Organizational Research Methods, vol. 1, no. 1, pp. 45-87, 1998.

[101] C. C. Manz and G. L. Stewart, "Attaining flexible stability by integrating total quality management and sociotechnical systems theory," Organization Science, vol. 8, no. 1, pp. 59-70, 1997. 
[102] M. J. Benner and M. Tushman, "Process management and technological innovation: a longitudinal study of the photography and paint industries," Administrative Science Quarterly, vol. 47, no. 4, pp. 676-706, 2002.

[103] P. S. Adler and B. Borys, "Two types of bureaucracy: enabling and coercive," Administrative Science Quarterly, vol. 41, no. 1, pp. 61-89, 1996.

[104] J. P. MacDuffie, "Road to "root cause": shop-floor problem-solving at three auto assembly plants," Management Science, vol. 43, no. 4, pp. 479-502, 1997.

[105] R. R. Lummus, L. K. Duclos, and R. J. Vokurka, "Supply chain flexibility: building a new model, global," Journal of Flexible Systems Management, vol. 4, no. 4, pp. 1-13, 2003.

[106] C. Dibrell, J. Down, and L. Bull, "Dynamic strategic planning: achieving strategic flexibility through formalization," Journal of Business and Management, vol. 13, no. 1, pp. 21-35, 2007.

[107] M. Beverland, "Adapting within relationships to adapt to market-led change: does relationship success lead to marketplace inertia?" Industrial Marketing Management, vol. 34, no. 6, pp. 577-589, 2005.

[108] M. L. Perry and A. T. Shao, "Incumbents in a dynamic Internet related services market: does customer and competitive orientation hinder or help performance?" Industrial Marketing Management, vol. 34, no. 6, pp. 590-601, 2005.

[109] J. Nakane, Manufacturing Futures Survey in Japan, Waseda University, System Science Institute, Tokyo, Japan, 1986.

[110] K. Ferdows and A. De Meyer, "Lasting improvements in manufacturing performance: in search of a new theory," Journal of Operations Management, vol. 9, no. 2, pp. 168-184, 1990.

[111] M. A. Noble, "Manufacturing strategy: testing the cumulative model in a multiple country context," Decision Sciences, vol. 26, no. 5, pp. 693-721, 1995.

[112] B. B. Flynn and E. J. Flynn, "An exploratory study of the nature of cumulative capabilities," Journal of Operations Management, vol. 22, no. 5, pp. 439-457, 2004.

[113] S. G. Winter, "Organizing for continuous improvement: evolutionary theory meets the quality revolution," in Evolutionary Dynamics of Organizations, J. A. Baum and J. V. Singh, Eds., pp. 90-108, University Press, Oxford, UK, 1994.

[114] D. I. Prajogo and A. S. Sohal, “The relationship between TQM practices, quality performance, and innovation performance. An empirical examination," International Journal of Quality and ReliabilityManagement, vol. 20, no. 8, pp. 901-918, 2003.

[115] R. S. M. Lau, "Strategic flexibility: a new reality for world-class manufacturing," Advanced Management Journal, vol. 61, no. 2, pp. 11-19, 1996.

[116] R. Sanchez, "Strategic flexibility in product competition," Strategic Management Journal, vol. 16, pp. 135-159, 1995.

[117] D. H. R. Price, R. Beach, A. P. Muhlemann, J. A. Sharp, and A. Paterson, “A system to support the enhancement of strategic flexibility in manufacturing enterprises," European Journal of Operational Research, vol. 109, no. 2, pp. 362-376, 1998.

[118] R. Beach, A. P. Muhlemann, D. H. R. Price, A. Paterson, and J. A. Sharp, "Manufacturing operations and strategic flexibility: survey and cases," International Journal of Operations and Production Management, vol. 20, no. 1, pp. 7-30, 2000.

[119] R. Palanisamy, "Strategic information systems planning model for building flexibility and success," Industrial Management E Data Systems, vol. 105, no. 1, pp. 63-81, 2005.

[120] R. G. Javalgi, T. Whipple, A. K. Ghosh, and R. B. Young, "Market orientation, strategic flexibility, and performance: implications for services providers," Journal of Services Marketing, vol. 19, no. 4, pp. 212-221, 2005.

[121] S. S. Rao, L. E. Solis, and T. S. Raghunathan, “A framework for international quality management research: development and validation of a measurement instrument," Total Quality Management, vol. 10, no. 7, pp. 1047-1075, 1999.

[122] Malcolm Baldrige National Quality Award. Criteria for Performance Excellence, United States Department of Commerce, National Institute of Standards and Technology, Washington, DC, USA, 2011. 


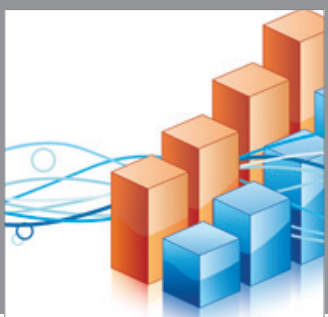

Advances in

Operations Research

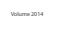

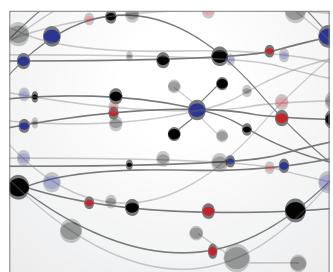

\section{The Scientific} World Journal
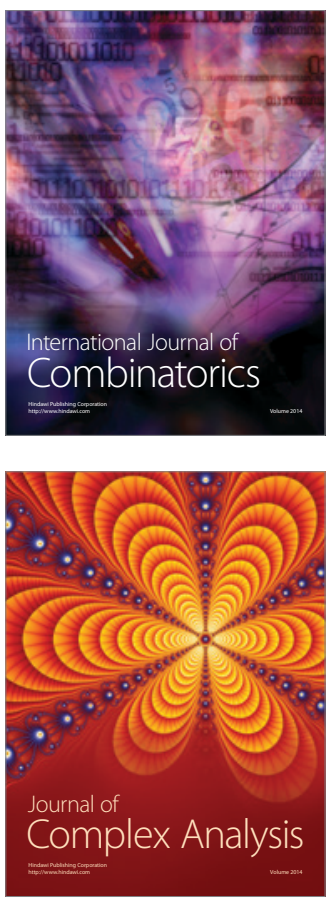

International Journal of

Mathematics and

Mathematical

Sciences
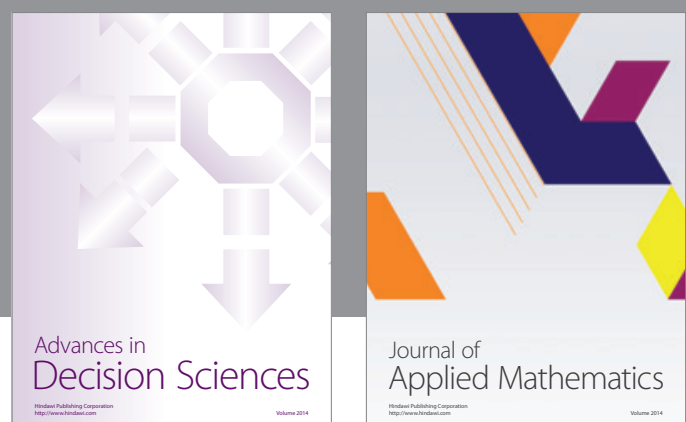

Journal of

Applied Mathematics
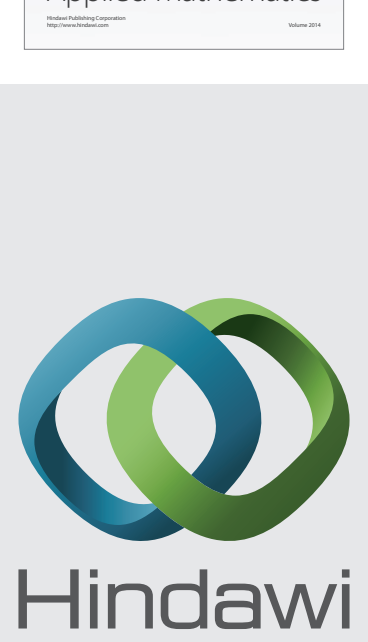

Submit your manuscripts at http://www.hindawi.com
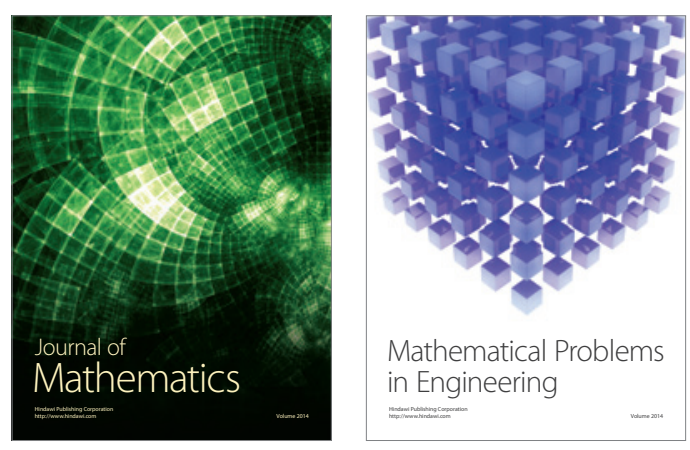

Mathematical Problems in Engineering
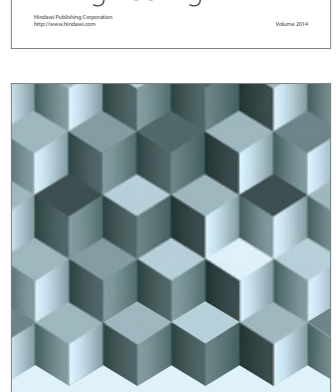

Journal of

Function Spaces
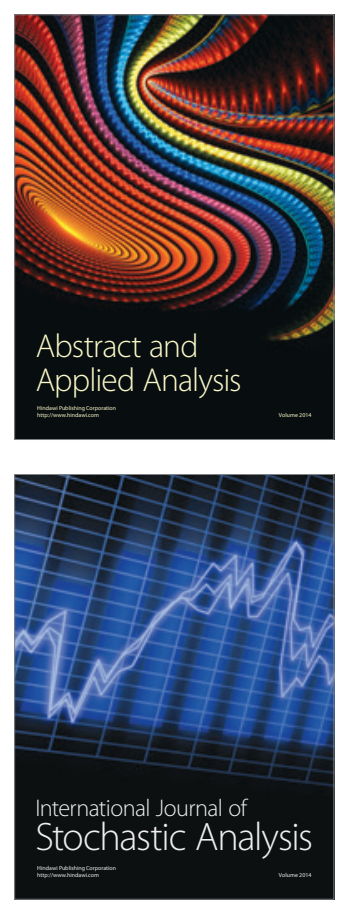

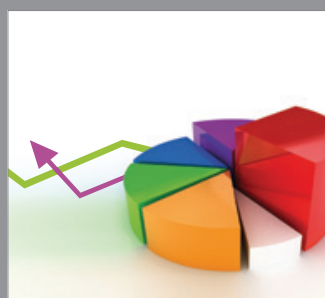

ournal of

Probability and Statistics

Promensencen
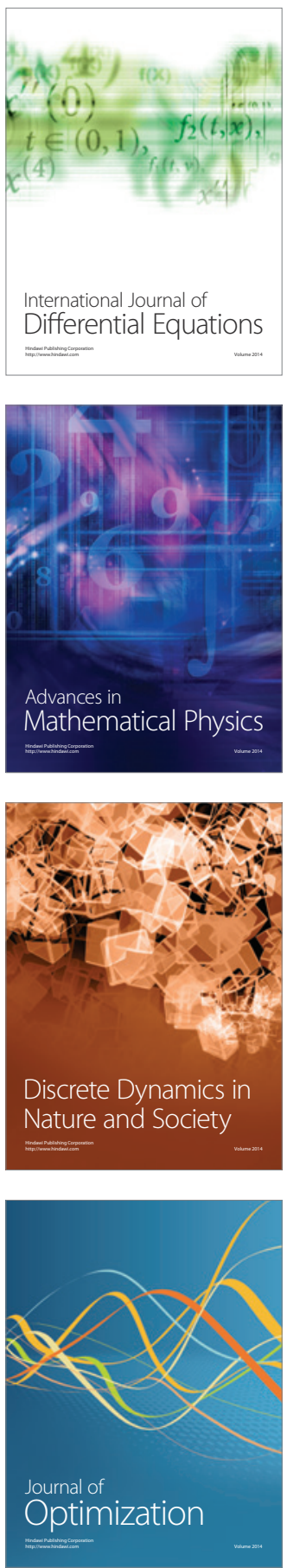